\title{
The Dimensionality of Cosponsorship Behavior in the House of Representatives
}

\author{
Andrés Carrizosa, Rice University
}

August 24, 2020

Word Count: 9945 


\begin{abstract}
Legislative stability exists in the House of Representatives, but there is not a consensus on whether this stability is produced by a Preference Induced Equilibrium (PIE), which predict that if preferences are unidimensional an equilibrium can be found at the position of the median legislator, or a Structure Induced Equilibrium (SIE), which predicts that multidimensional legislative preferences must be constrained by institutions to produce stable outcomes. While both explanations predict that roll-call behavior will be unidimensional, they make competing predictions for less constrained behavior such as cosponsorship behavior. By relying on Bayesian item-response methods that allows for the assessment of dimensionality for both cosponsorship behavior and roll-call behavior on a comparable scale - which has been problematic in the past-I provide evidence in support of a SIE in the House. While roll-call behavior is unidimensional, only around $30 \%$ of cosponsorship behavior is explained by the first dimension of legislative preferences.
\end{abstract}




\section{Introduction}

Despite Arrow's (1951) prediction of cycling majorities and unstable outcomes under conditions of majority rule, legislative behavior in the U.S. House of Representatives has mostly produced stable policy outputs (Tullock and Brennan, 1981). In attempting to account for why so much stability exists, two broad families of explanations have been proposed. The first, called Preference Induced Equilibrium (PIE) argues that if legislative preferences are unidimensional, then legislative stability is easily explained as the equilibrium outcome of the chamber would be found at the preferences of the median legislator (Black, 1948; Krehbiel, 1998). The second, called Structure Induced Equilibriums (SIE) argues that if legislators have multidimensional preferences legislative stability is only possible through institutions that create stable policy outputs (Shepsle and Weingast, 1981; Aldrich, 1989). Unfortunately, to this day we have not been able to definitively say which of these two mechanisms is more relevant for explaining legislative stability in the House.

A critical limitation to discerning whether a PIE or a SIE takes place in the House is that, although widely used, roll-call data is not ideal for differentiating between these two causal mechanisms for stability. This is because both PIEs and SIEs predict that roll-call data will be unidimensional, making it difficult to distinguish between these mechanisms. PIEs expect roll-call data to be unidimensional because, since preferences are unidimensional, these unidimensional preferences will be directly reflected as behavior on the floor Krehbiel, 1993, 1998). In contrast, SIEs predict that roll-call behavior will be unidimensional because institutions constrain multidimensional preferences into producing unidimensional behavior (Shepsle and Weingast, 1981). Therefore, the use of roll-call data for discerning between a PIE and a SIE is quite limited.

In this paper I propose attempting to distinguish between a PIE and an SIE in the House of Representatives by using cosponsorship data. The advantage of these data is that PIEs and SIEs do have very different expectations for the structure of cosponsorship data. Given that PIEs assume that legislator preferences are ideological and unidimensional, then cospon- 
sorship behavior should be unidimensional as well, since just like roll-call data they should be a reflection of underlying ideological, unidimensional preferences. In contrast, a SIE would assume that underlying preferences were distributive and multidimensional, and therefore legislative stability would only be able to be produced if institutions constrained roll-call behavior into unidimensionality (Shepsle and Weingast, 1981). Therefore, if a SIE exists, we would expect cosponsorship behavior to be multidimensional given that this behavior is not constrained by institutions in the same way that roll-call behavior is.

The dimensionality of cosponsorship behavior has been analyzed in the past by Talbert and Potoski (2002) and Jones, Talbert and Potoski (2003). These authors used NOMINATE procedures to estimate the dimensionality of cosponsorship data, and their findings suggested the multidimensionality of cosponsorship behavior. However, Alemán et al. (2009) and Desposato, Kearney and Crisp (2011) argued that NOMINATE methods may overestimate the dimensionality of cosponsorship behavior because these methods were developed for rollcall data. In roll-call data a "nay" vote explicitly means opposition to a bill, but with cosponsorship data a failure to cosponsor may or may not mean opposition to a bill. Failure to account for these different data generating processes, they argued, may bias dimensionality measures upward. Therefore, existing comparisons between the dimensionality of roll-call behavior and cosponsorship behavior are still problematic.

In this paper I suggest an alternative method for estimating the dimensionality of both roll-call and cosponsorship data on a common scale, and this assessment relies on Bayesian item-response theory (IRT) methods. Leaning on Desposato, Kearney and Crisp s (2011) finding that the first dimension is equally identifiable in both cosponsorship data and rollcall data, in this paper I first create estimates of legislative ideal points from both these data sources, and then I verify that both sets of estimates capture very much the same thing. Then, I measure the extent to which this first dimension explains both cosponsorship and roll-call behavior. If preferences were truly unidimensional, as expected by a PIE, then this first dimension would explain an overwhelming amount of both cosponsorship and roll- 
call data. However, if preferences were multidimensional, as expected by a SIE, then very little cosponsorship behavior would be explained by the first dimension while most roll-call behavior would be explained by the first dimension.

My findings suggest that a SIE is the dominant mechanism through which stability of legislative outputs is created in the U.S. House of Representatives. While the first dimension of legislative preferences does explain an overwhelming amount of roll-call behavior, only a small subset of cosponsorship behavior is explained by the first dimension-around $30 \%$ of behavior. Although this finding relies on the fact that many cosponsorship decisions are lopsided or single-authored bills, I also provide evidence to show that even these lopsided and single-authored bills do not conform to what we would expect to see if preferences were unidimensional. Unidimensional models would expect only peripheral, and not central, legislators to be in the minority of lopsided and single-author bill signings, because the only way to create lopsided bill signings in unidimensional spaces is through placing cutpoints at ideological extremes - thus separating a few extremists from everyone else. By verifying that single-author and lopsided cosponsorship behavior is not more prominent among extreme legislators than centrist legislators on the first dimension, I also provide evidence to support the assertion that cosponsorship behavior is multidimensional.

This paper concludes by proposing research avenues that can deepen our understanding of how exactly SIEs function to compress multidimensional preferences into unidimensional behavior. Specifically, 1) researchers can model multidimensional preferences more explicitly in their attempts to understand legislative behavior, and they can further adapt legislative models of parties to account for multidimensional preferences; 2) researchers can explore how institutions exogenous to the legislature can affect the dimensionality of legislative behavior through strategic anticipation of the impacts of those exogenous institutions; and 3) researchers can trace how support (or opposition) for a bill evolves throughout the cosponsorship process before arriving to the point where it actually has to be voted on on the floor. By carrying out this work, researchers of legislative politics will be better able to account 
for how the multidimensionality of preferences uncovered by this research project can lead to stable outcomes and unidimensional voting behavior on the chamber floor.

\section{Theoretical Background}

The dimensionality of legislator preferences is extremely important for understanding legislative outcomes. If legislative preferences are unidimensional (and single-peaked) then a policy equilibrium exists at the preferences of the median legislator (Krehbiel, 1998; Black, 1948). In contrast, when preferences are multidimensional, then policy instability is expected Arrow, 1951), and in this case stability can only be produced through the use of institutions (Shepsle and Weingast, 1981; Aldrich, 1989). A large part of the reason why the debate between PIEs and SIEs has raged on for so long in the literature of legislative politics has to do with our lack of clarity about what "preferences" mean (Smith, 2007). Often, our misunderstandings about preferences are both conceptual and methodological.

The first, conceptual issue that is often unclear about legislator preferences is whether these preferences are ideological or electoral. Ideology is a concept where individual issues are packaged together into logical structures or "idea constraints" that contain, and predict, many individual behaviors (Converse, 1964). This concept is the foundation of latent measures of ideology where a "basic space" is assumed to be able to capture and summarize behavior across a larger space of individual policy issues (Poole, 2005). Thus, ideology inherently reduces the dimensionality of the policy space, and therefore if preferences are assumed to mean strong, ideological preferences, then we would expect preferences to be low- or even uni-dimensional. Electoral preferences on the other hand, are likely to create multidimensional preferences. If legislators represent different districts that have different needs and interests, a focus on extracting particularistic benefits for one's district is likely to create multidimensional preferences (Shepsle and Weingast, 1981; Mayhew, 1974).

The second, methodological, issue entails situations where expressed preferences may not match a legislator's true preferences. Throughout the studies of legislatures, an important 
way legislative preferences have been measured has been through the use of roll-call data. However, virtually all legislative scholars know that roll-call data may not represent legislators' true preferences because this behavior is constrained by parties, legislative institutions, and selection problems (Cox and McCubbins, 2005; Hug, 2010; Shepsle and Weingast, 1981; McCarty, 2016); and scholars have also argued that these parties, institutions and selection problems may artificially reduce the dimensionality of legislative behavior (Dougherty, Lynch and Madonna, 2014; Wright and Schaffner, 2002). Thus, although still extremely useful for understanding a large portion of legislative behavior, roll-call voting as a measure of the dimensionality of legislative preferences is limited because of the extent to which it is constrained by parties, institutions and selection problems.

With these conceptual and methodological issues, we can immediately see why roll-call data may not be ideal for understanding the dimensionality of legislative preferences. This is because both SIEs and PIEs would expect unidimensional roll-call behavior. SIEs expect true, multidimensional preferences to be constrained by institutions leading to unidimensional roll-call behavior (Shepsle and Weingast, 1981). PIEs expect true, unidimensional preferences to be reflected on roll-call behavior without much interference from legislative institutions or parties (Krehbiel, 1993).

However, the advantage of using cosponsorship data is that the expectations of SIEs and PIEs vary widely when behavior is less constrained. SIEs expect unconstrained behavior to be multidimensional, reflecting the particularistic, electoral preferences of legislators (Shepsle and Weingast, 1981). In contrast, PIEs, because they produce stability through "idea constraints" contained within the heads of legislators, expect that even when behavioral constraints are lifted, unidimensional behavior should be expressed because behavior would simply match the structure of legislators' unidimensional preferences. Therefore, while SIEs and PIEs create expectations of roll-call behavior that are difficult to distinguish, their expectations of less-constrained cosponsorship behavior varies widely.

This is not to say that cosponsorship behavior really represents the untainted beliefs or 
"true preferences" of legislators. What I argue that cosponsorship is better at capturing the individualistic incentives that legislators face. Cosponsorship behavior is likely to be a function of both ideology and electoral preferences. However, roll-call data is likely to be a function of ideology, electoral preferences and legislative institutions - which may create party pressures through selection problems (Cox and McCubbins, 1993, 2005). The key here is that legislative institutions are vital for the functioning of SIEs, but they are unimportant for the functioning of PIEs. Therefore, if the dimensionality of cosponsorhsip behavior is different from the dimensionality of roll-call behavior, then that would indicate that legislative institutions - that affect roll-call behavior but not cosponsorship behavior - are important to the construction of legislative stability.

\section{Previous Analysis of the Dimensionality of Cosponsorship Be- havior, and Unresolved Issues}

The dimensionality of cosponsorship behavior in the U.S. House of Representatives has been analyzed before. Talbert and Potoski (2002) and Jones, Talbert and Potoski (2003) showed the mismatch between multidimensional preferences before legislative institutions affect behavior (cosponsorship data) and unidimensional preferences after legislative institutions affect behavior (roll-call data), and through this mismatch they argued that a SIE must be creating stability. They concluded by showing that cosponsorship behavior did have higher dimensionality than roll-call behavior, and they described the content of the four most relevant dimensions of cosponsorship behavior: 1) the party and ideology dimension, 2) the law and order/foreign affairs and civil rights dimension, 3) the agricultural/environmental dimension, and the 4) fiscal affairs dimension.

However, Alemán et al. (2009) responded by arguing that applying W-NOMINATE to cosponsorship data is not methodologically sound. Alemán et al. proposed using socialnetwork analysis to estimate ideal points using cosponsorship behavior instead. With their 
novel method the authors found that "two dimensions explain the vast majority of the variance in the United States cosponsorship data," and that their discrepancy with Talbert and Potoski (2002) was because "[T]he NOMINATE algorithm... treats the decision not to cosponsor a bill as akin to a vote against a bill on the floor. Since the vast majority of bills have relatively few cosponsors, applying this algorithm to the two-mode cosponsorship matrix results in most cutpoints being set at spatial extremes." They argued that because of these extreme cutpoints, and because NOMINATE drops lopsided votes leading to a drop of most cosponsorship bills that tend to have few signatures, then using NOMINATE on cosponsorship behavior artificially inflates estimates of dimensionality.

Finally, in response to Alemán et al. (2009), Desposato, Kearney and Crisp (2011) used simulated data to explore how varying data generating processes (DGP) affected how closely W-NOMINATE and PCA retrieved the true ideal points. The different DGP they considered were 1) the Sincere Model, 2) the Random Model, 3) the Neighbor Model, and the 4) Network Model. Of all these DGPs, only the Sincere Model assumes that failure to sponsor a bill entails true opposition to the bill, and therefore only this model matches the assumptions under which NOMINATE models were constructed. One of the main findings of Desposato, Kearney and Crisp s (2011) work is that both PCA and W-NOMINATE estimates of dimensionality of preferences (eigenvalues) are always biased upwards when the DGP is not the Sincere Model - regardless of which estimation procedure is used.

In summary, we still do not have a definitive understanding about whether cosponsorship behavior is mostly unidimensional or multidimensional. Talbert and Potoski (2002) found that preferences were four-dimensional, Alemán et al. (2009) found that preferences were two-dimensional, but Desposato, Kearney and Crisp (2011) called into question both these findings by suggesting that due to the fact that the DGP of cosponsorship behavior is different than the DGP of roll-call data, then both of these dimensionality findings may be biased upwards. In other words, we still do not have conclusive evidence to show whether cosponsorship behavior is in fact high-dimensional - suggesting a SIE given unidimensional 
roll-call behavior - or whether cosponsorship behavior is unidimensional - suggesting a PIE given unidimensional roll-call behavior.

\section{Data}

In order to analyze the dimensionality of cosponsorship behavior, and compare this to the dimensionality of roll-call data, I have relied on two well-known sources of data. Roll-call data was retrieved from Voteview, which assembled legislative roll-call behavior from the first Congress to the 115th (Lewis et al. 2020). In terms of cosponsorship data, although Alemán et al. (2009) used the cosponsorship data assembled by Fowler (2006), I opted to re-scrape cosponsorship data from congress.gov because I was interested in assessing the dimensionality of original cosponsorship behavior against the dimensionality of final cosponsorship behavior.

I chose to analyze both original and final cosponsorship data because Kessler and Krehbiel (1996) argued that cosponsorship behavior should be seen as a process rather than as a final product, where legislators see their available options, gain information about projects, promote their own projects, and anticipate the success or failure of a bill on the floor before deciding whether to sign onto a bill. Furthermore, as hypothesized by Talbert and Potoski (2002), this information-gathering and floor-success anticipation may lead to a reduction in the dimensionality of cosponsorship behavior as time goes by. However, whether this dimensional reduction actually takes place is an empirical question, so throughout this paper I will be analyzing not only the dimensionality of final cosponsorship behavior, but also the dimensionality of original cosponsors of a bill. That being said, I replicated Alemán et al.'s (2009) analysis using both their own data and my re-scraped data for the years we had in common, and our findings were virtually the same. Therefore, although I re-assembled Fowler s (2006) database to explore information about original cosponsors, in most respects our data are the same.

Cosponsorship data exists for a shorter period of time than roll-call data does. Prior to the 96th Congress there was a 25 cosponsor limit per bill in the House. Furthermore, the 
97th Congress was the first one where complete data for amendments were available. Despite the fact that amendments almost never cosponsored, all my analysis will begin in the 97 th Congress because from this point on all the data is complete, and cosponsorship behavior is less restricted (Fowler, 2006). Section 1 of the Appendix provides a summary of all the data I based my analysis on.

\section{Previous Methodological Limitations}

In the previous sections we saw that Talbert and Potoski (2002) used W-NOMINATE to argue that cosponsorship behavior had four dimensions. However, Alemán et al. (2009) argued that this dimensionality is too high and that with their PCA method only two dimensions became relevant to cosponsorship behavior. Finally, Desposato, Kearney and Crisp (2011) argued that both PCA and W-NOMINATE were likely to overestimate dimensionality if cosponsorship behavior was not generated by the Sincere Model DGP. In this section I will argue that the APRE measure used by Talbert and Potoski (2002) and the eigenvalues used by Alemán et al. (2009) and Desposato, Kearney and Crisp (2011) may be less than ideal for assessing the dimensionality of cosponsorship data.

APRE stands for Aggregate Proportional Reduction of Error, and it is a common measure used to gauge the dimensionality of W-NOMINATE estimates. Intuitively, APRE takes the minority vote as an error baseline, and then it estimates the extent to which a given W-NOMINATE model can improve on this baseline of errors $1^{1}$ However, in relation to cosponsorship data, the main limitation of APRE is that cosponsorship behavior is not voting. That is, the minority vote baseline is less than ideal because there is no minority vote in cosponsorship behavior. In fact, since bills will virtually never be cosponsored by a majority of legislators, the "yeas" will always be in the "minority" of cosponsorship behavior. In other words, improving upon the minority baseline in cosponsorship behavior may not carry the same intuitive sense that it does with roll-call data because minority votes are

\footnotetext{
${ }^{1}$ The complete formula for how to calculate APRE is included in Section 2 of the Appendix.
} 
substantively different in these two DGPs.

In contrast, Alemán et al. (2009) and Desposato, Kearney and Crisp (2011) used eigenvalues to assess the dimensionality of cosponsorship behavior. Ostensibly this makes sense because both PCA and W-NOMINATE produce eigenvalues, so relying on a common measure seems intuitive. However, Desposato, Kearney and Crisp (2011) found that eigenvalues extracted by both PCA and W-NOMINATE overestimate the dimensionality data produced by a DGP that is not the Sincere Model. This means that if we use PCA or W-NOMINATE to create ideal points with roll-call data and cosponsorship data and we tried to compare the dimensionality of these two sets of estimates, our cosponsorship estimates of dimensionality would possibly be inflated - even if preferences were held constant. This, of course, is a severe limitation if we are trying to compare the dimensionality of cosponsorship and roll-call behavior.

\section{A Bayesian Alternative}

In order to explore the dimensionality of cosponsorship data more directly, I have opted to move away from the frequentist frameworks of PCA and W-NOMINATE, and towards a Bayesian implementation of item-response theory (IRT) that can be used to estimate legislator ideal points (Jackman, 2001). Although the resulting ideal points tend to be quite similar between W-NOMINATE and IRT, the theoretical paradigms underlining these two procedures are different. Whereas W-NOMINATE is built on rational-choice theory, Bayesian IRT was originally intended to create latent measures for student intelligence or "capacity" in test-taking (Poole, 2005). Through MCMC sampling, this method simultaneously uncovers parameters for capacity of the student, the difficulty of the question, and the discrimination of the question - how well a question divided smart from not-so-smart students. In the context of politics, capacity is interpreted as ideology, difficulty is conceptually similarmore difficult bills are less likely to gain support_-, and discrimination is also conceptually similar - higher discrimination parameters indicate bills that more strongly divide legislators 
on each ideological dimension. These three parameters are retrieved through this formula in a unidimensional model:

$$
\begin{gathered}
\operatorname{Pr}\left(\operatorname{Cosp}_{i j}=1\right) \sim \operatorname{Bernoulli}(\theta) \\
\theta=\Phi\left(\alpha_{j}-\beta_{j} x_{i}\right)
\end{gathered}
$$

Where $\Phi$ is the standard normal distribution (a probit-link function), $\alpha_{j}$ are the difficulty parameters, $x_{i}$ are the estimates for the ideology of legislators, and $\beta_{j}$ are the discrimination parameters. The discrimination parameter provides the slope for a probit line for each bill, and the difficulty parameter provides the intercept for each bill. Finally, these parameters, although estimated jointly, are indexed differently as the $x$ parameter is indexed by legislator (i), whereas both $\alpha$ and $\beta$ parameters are indexed by roll-call (j).

The way Bayesian IRT estimates the dimensionality of the policy space is also different from W-NOMINATE and PCA. Instead of using APRE2 or eigenvalues, Bayesian IRT simply observes the proportion of bills where $\beta$ is significantly different from zero. The higher the proportion of explained bills by a single dimension, the lower the dimensionality of behavior.

The IRT framework is convenient because Desposato, Kearney and Crisp (2011) found, through simulations, that with a large $n$ the estimation of first-dimensional ideal points under different DGP are mostly unbiased. This finding is useful for my purposes because, if the first-dimensional ideal points are the same for cosponsorship data and roll-call data, then independently estimated ideal points should be highly correlated and mostly interchangeable. Once these unbiased ideal points are estimated, the issue of dimensionality can be addressed by exploring how much cosponsorship behavior can be accounted for by unidimensional ideal points. Following the logic of the Bayesian dimensionality assessments is therefore quite straightforward for both roll-call and cosponsorship data.

Furthermore, since first-dimensional ideal points are unbiased regardless of which data

\footnotetext{
${ }^{2}$ Strictly, APRE can also be estimated for IRT, but it may not be ideal given my previous argument.
} 
they are produced on, it is even possible to explore the extent to which ideal points derived from roll-call data explain cosponsorship behavior. This can simply be done by using roll-call ideal points as independent variables in probit regression models that estimate each cosponsorship decision. Then, we can observe the extent to which the slope coefficients of these models are significant. This process approximates what bayesian IRT does to assess dimensionality, but it does so using exogenously created ideal points rather than simultaneously estimated ideal points.

There is a slight difference between the probit line derived from Bayesian IRT and the line that can be derived from an independently estimated probit regression for a given bill. The function of the probit line estimated by Bayesian IRT was shown above. In contrast, a simple probit regression model with legislator ideal points as an independent variable and yea/nay or sponsor/not-sponsor decisions as the dependent variable would be estimated through this function:

$$
\begin{gathered}
\operatorname{Pr}\left(\operatorname{Cosp}_{i}=1\right) \sim \operatorname{Bernoulli}(\theta) \\
\theta=\Phi\left(\alpha+\beta x_{i}\right)
\end{gathered}
$$

Which is a simple probit-linked linear aggregator with the intercept $\alpha$ and the coefficient $\beta$, and $x_{i}$ represents the ideal point of each legislator. These regressions would be carried out for each roll-call or cosponsorship item $(\mathrm{j})$.

The big difference between these probit regressions and the IRT model depicted above, is that $x_{i}$ is simultaneously estimated to $\beta_{j}$ and $\alpha_{j}$ in the IRT model. In contrast, in these probit regression models, ideal points, $x_{i}$, are taken as the independent variable, and $\alpha$ and $\beta$ are estimated with a probit regression for each cosponsorship or roll-call item. In both cases, though, the proportion of $\beta$ that are significant for all roll-call or cosponsorship can be used as measures of dimensionality. Whether they are jointly estimated Bayesian IRT betas, or whether they are independently estimated probit regression betas, the higher the proportion of significant betas of cosponsorship or roll-call behavior, the more unidimensional that given 
behavior is $3^{3}$

In summary, the adequacy of using probit models to assess the dimensionality of cosponsorship behavior depends on my ability to show that ideal points produced with cosponsorship and roll-call data are highly correlated. If ideal points calculated from roll-call behavior and cosponsorship behavior show the same thing, then we can assess dimensionality of both forms of behavior by simply seeing the extent to which this common first dimension explains each form of behavior. This can be done by checking the proportion of betas that are significantly different from zero in Bayesian IRT models, or we can also use exogenously estimated ideal points as independent variables of probit regression models that predict each cosponsorship or roll-call item as a series of dependent variables, and we can see the extent to which these probit regression models have significant beta coefficients. In both cases the proportion of significant betas signals the extent to which the first dimension explains cosponsorship or roll-call behavior. To be able to do this, however, we have to be sure that first-dimension ideal points estimated from cosponsorship data and roll-call data capture the same thing. Therefore checking whether this is the case is what I turn to in the next section.

\section{Evidence For Unbiased First-Dimensional Ideal Points}

In order to show that the chosen estimation procedure and the data generating process have minimal impacts on the extracted ideal points, I will first hold the estimation procedure constant and I will vary the data on which that estimation procedure is carried out to show that ideal points are similar regardless of which data they are carried out on. Then, I will hold the data constant and I will estimate ideal points using different estimation procedures on this constant data. By holding estimation procedures constant and varying data, and by holding data constant and varying estimation procedures, and showing that neither of these

\footnotetext{
${ }^{3}$ Section 3 of the Appendix shows an example of Bayesian IRT parameters and probit regression parameters creating predictions for a single cosponsorship decision, to show that these two models produce very similar predictions despite their different constructions. I also show that because roll-call ideal points are so similar from cosponsorship ideal points, a probit regression that estimates a cosponsorship decision with roll-call ideal points as the independent variable also produces a very similar linear prediction.
} 
changes make substantively important differences in estimated ideal points, we can show that the problem of biased ideal points derived from cosponsorship data is smaller than previous researchers have expected.

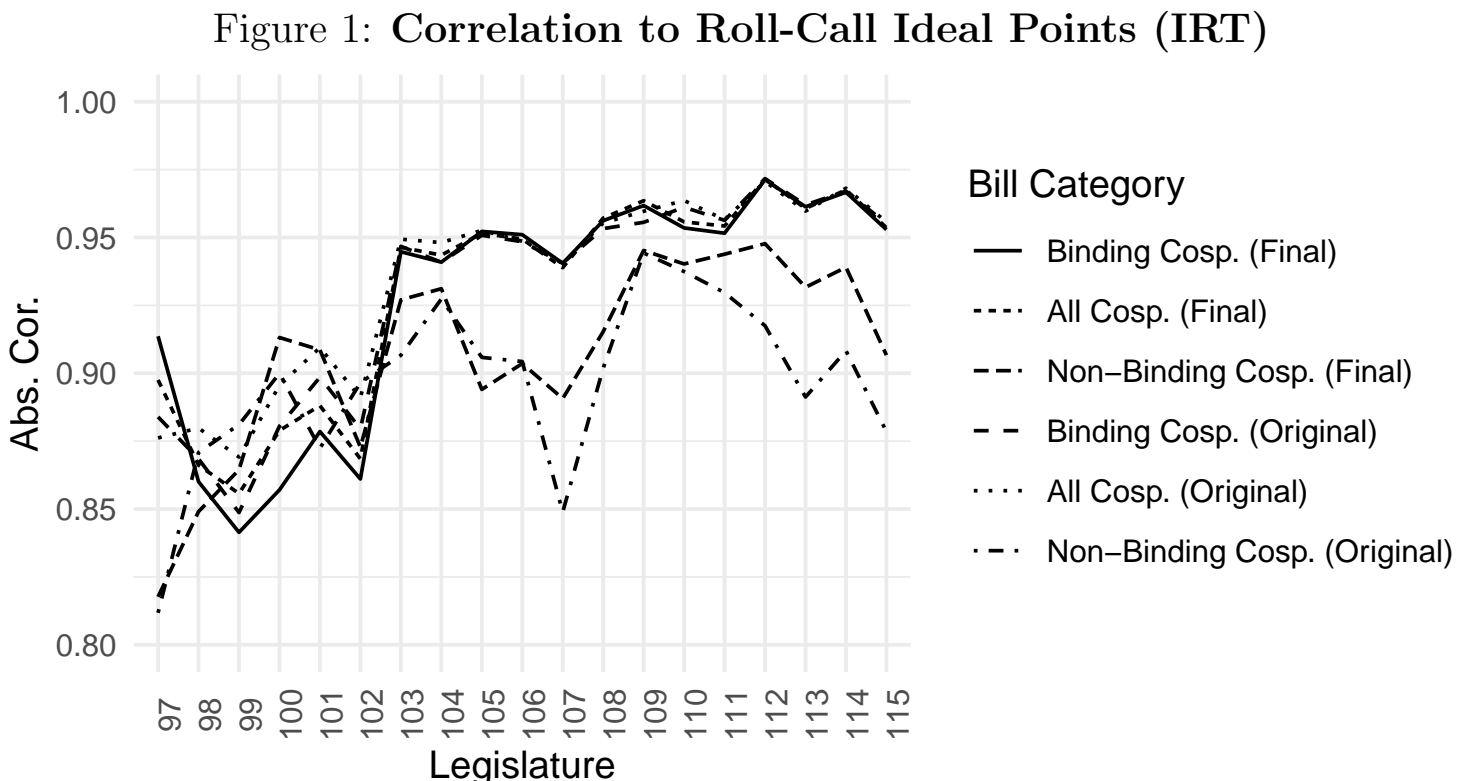

Figure 1 shows the correlation of ideal points estimated from a variety of different subsets of cosponsorship data to ideal points estimated from roll-call data. Cosponsorship data exists on House Bills, House Concurrent Resolutions, House Resolutions, House Joint Resolutions and Amendments. House Bills, House Joint Resolutions and Amendments are binding pieces of legislation, which means that if they pass they can be implemented with the force of law. On the other hand, House Resolutions and House Concurrent Resolutions are not binding. Therefore, in addition to estimating ideal points for all cosponsorship behavior, I also separately estimated ideal points using these two categories of "Binding" and "Non-Binding" bills because the choice to sponsor binding and nonbinding legislation may potentially be a different calculus in the minds of legislators. For each of these three categories of cosponsorship behavior (all, binding and nonbinding) I also estimated ideal points using data from original cosponsors of each bill (original) and I estimated ideal points using data from final cosponsors of each bill (final). Therefore, for each Congress I was able to estimate six sep- 
arate ideal point estimates for all legislators, and I compared these six cosponsorship ideal point estimates to roll-call ideal points for each Congress. All estimates in this figure were carried out using the PSCL package in $\mathrm{R}$, which generates ideal points using a Bayesian IRT procedure (Jackman, 2001; Clinton, Jackman and Rivers, 2004).

In general, figure 1 shows that is some small variability in correlations to roll-call ideal points by year and by data source. Specifically, from the 103rd Congress, cosponsorship ideal points seem to have a higher correlation to roll-call ideal points among binding bills. However, non-binding bills, of both the original cosponsors and final cosponsors, seem to maintain lower levels of correlations to roll-call ideal points from the 103rd Congress on.

This change may reflect the strengthening of party influence on legislative behavior that has usually been found in Senate and House behavior in the United States around 1994 (Lee, 2016; Ramey, 2015). Because of strengthened party influence, the partisan dimension may have become more clear, and therefore more strongly related across data sources. Interestingly, though, that effect seems to be weaker on nonbinding bills. This may indicate that although partisan influence became stronger, true preferences may not have changed as much. This is because parties are less likely to pressure on non-binding bills, allowing legislators to behave in a more unconstrained way in the cosponsoring of this kind of legislation.

However, the big picture of all these comparisons is that ideal points estimated from any of these data sources are really quite similar. Figure 1 shows that cosponsorship ideal points always have correlation coefficients above .8 with roll-call ideal points. In essence, despite the slight differences between ideal points estimated solely from nonbinding bills, all these measures are capturing very much the same thing. Furthermore, before the 103rd Congress there is not a big difference between binding and non-binding bills in their relationship to roll-call behavior.

The second task of this section was to show that by holding data sources constant, and varying estimation methods, ideal point estimates were mostly unbiased as well. Figure 2 shows what happens when we hold the data constant, and we run different ideal point 
estimation procedures on these constant data. For this figure, I also subsetted cosponsorship data into all bills, binding bills and nonbinding bills. I also checked to see if there was any difference with original cosponsorship data and final cosponsorship data for these three categories. Finally, this figure also shows changes in estimation procedures for roll-call data. I compared ideal points derived from W-NOMINATE, Bayesian IRT, and PCA. The main thing that Figure 2 shows is that all measures are highly correlated on the ideal points estimated for the first dimension. This also provides evidence to show that cosponsorship datasets and roll-call datasets in the House are large enough that all ideal point estimation methods provide similar first-dimensional estimates to what we would expect from roll-call data regardless of estimation method. All in all, then, the identification of the first dimension of legislative preferences is therefore not that problematic when large amounts of data are available, despite the different DGPs that may be underlying behavior (Desposato, Kearney and Crisp, 2011). 


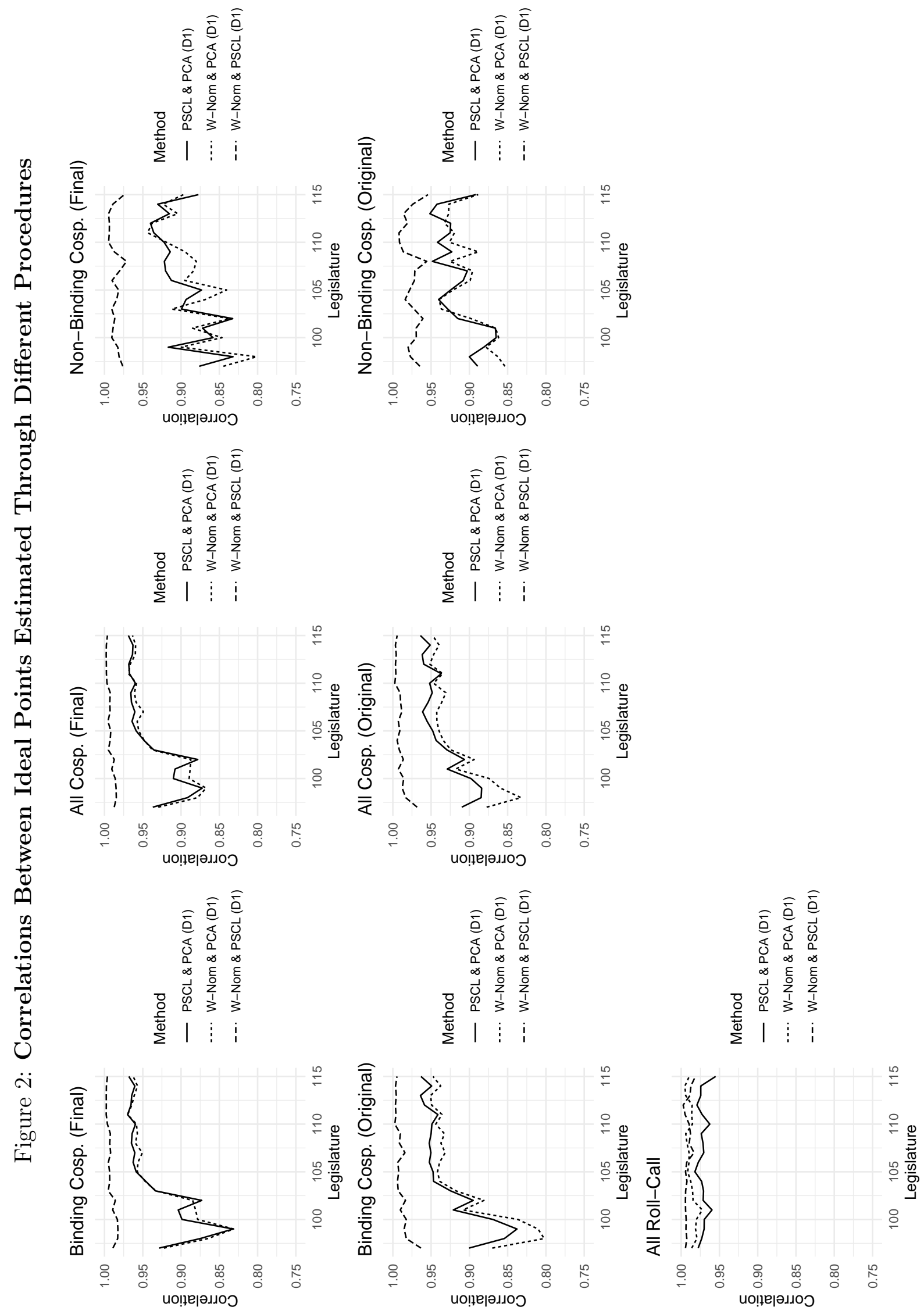


The fact that ideal points are mostly unbiased regardless of whether they are estimated with roll-call or cosponsorship data, implies that Bayesian IRT betas and probit regression betas will provide similar assessments of dimensionality regardless of which ideal points are used. Although not presented here, in Section 4 of the Appendix I perform a variety of tests that show that in fact bill-level parameters estimated from Bayesian IRT and from independent probit regressions show high levels of agreement. Probit regressions even show very similar beta estimates for cosponsorship behavior regardless of whether probit regressions use roll-call or cosponsorship ideal points as independent variables. Having shown that bias in the estimation of first-dimensional ideal points is non-problematic given the large availability of data at my disposal, and having argued that these unbiased ideal points can be used to create measures of dimensionality that are comparable between cosponsorship and roll-call data, it is now possible to move on to the assessment of dimensionality of cosponsorship data in relation to roll-call data.

\section{Assessment of Dimensionality}

Figure 3 shows the first assessment of dimensionality. This figure shows three lines. The dashed line (\% Sig. IRT Betas Roll) shows the proportion of Bayesian IRT betas that were significant in predicting roll-call behavior. I have simply included this measure of roll-call dimensionality as a comparison baseline on which to compare the dimensionality measures of cosponsorship behavior. As expected, the data is almost completely explained by the first dimension as Bayesian IRT betas are overwhelmingly significant in explaining roll-call behavior (Poole and Rosenthal, 1997).

Moving on to cosponsorship data, the solid line (\% Sig. IRT Betas Cosp.) shows the extent to which Bayesian IRT betas are significant in explaining cosponsorship data. According to these IRT beta parameters, around $75 \%$ of cosponsorship behavior is explained by the first dimension. This indicates that cosponsorship behavior does seem to be of higher dimensionality than roll-call behavior because less cosponsorship behavior can be explained 
by the first dimension. However, up to this point the difference between these two data sources does not seem to be very dramatic.

Figure 3: Assessment of Dimensionality (Non-Lopsided)

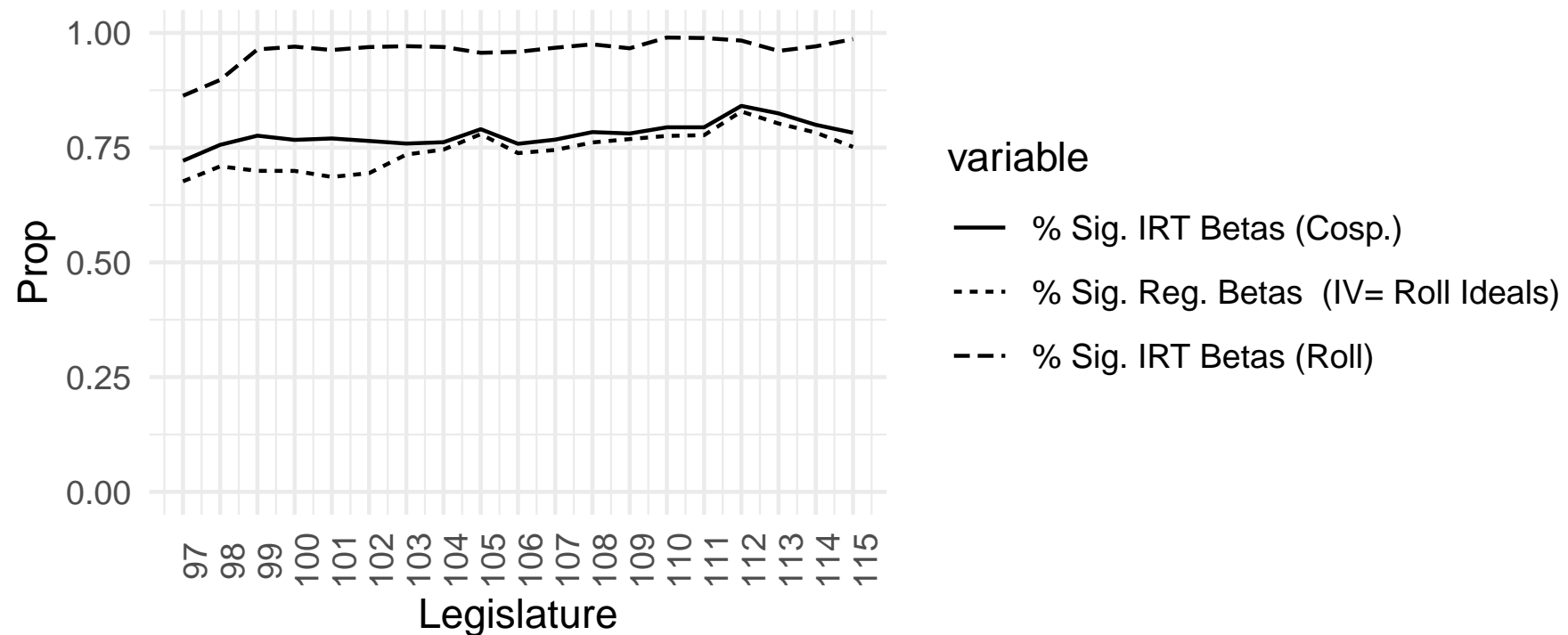

Finally, the dotted line (\% Sig. Reg. Betas IV=Roll Ideals) shows the extent to which first-dimensional roll-call ideal points predict cosponsorship behavior. This line shows the proportion of exogenously-created probit regression coefficients that significantly predict cosponsorship behavior. The proportion of significance of these estimates are consistently lower than simultaneously estimated Bayesian IRT betas, but not by much. Therefore, even when roll-call ideal points are used to estimate cosponsorship behavior, the assessment of dimensionality provided by these ideal points is very similar to the assessment provided by Bayesian IRT betas that are simultaneously estimated to cosponsorship ideal points. All in all, these two indicators of dimensionality may be taken to suggest that cosponsorship behavior is higher dimensional than roll-call behavior-because less cosponsorship behavior is accounted for by the first dimension-but the first dimension does seem to explain more behavior than we may have expected.

However, the findings presented in Figure 3 are a bit misleading because most ideal 
point estimation procedures automatically drop lopsided data. If, of all those that are present in a roll-call voting situation, the proportion of yeas or nays of a given roll-call are smaller than $2.5 \%$ of those present, then that vote is not used for the estimation of ideal points (Jackman, 2001). This problem of lopsided data is even a bit more pronounced for cosponsorship data because there are no "absences." Therefore, the the $2.5 \%$ yea and nay threshold always applies over all legislators, while it only applies to present legislators in roll-call data. That is, if there are 435 legislators, then cosponsorship decisions have to have at least 11 yeas and nays in order to not be dropped. Section 1 in the Appendix, which summarizes the data used for this study, shows that only 15-30\% of cosponsorship items and only $10-18 \%$ of original cosponosorship items clear this restriction. Therefore, the estimates of dimensionality presented in Figure 3 only shows the extent to which the first dimension explains a severely subsetted portion of cosponsorship behavior.

\section{Figure 4: Assessment of Dimensionality With Lopsided}
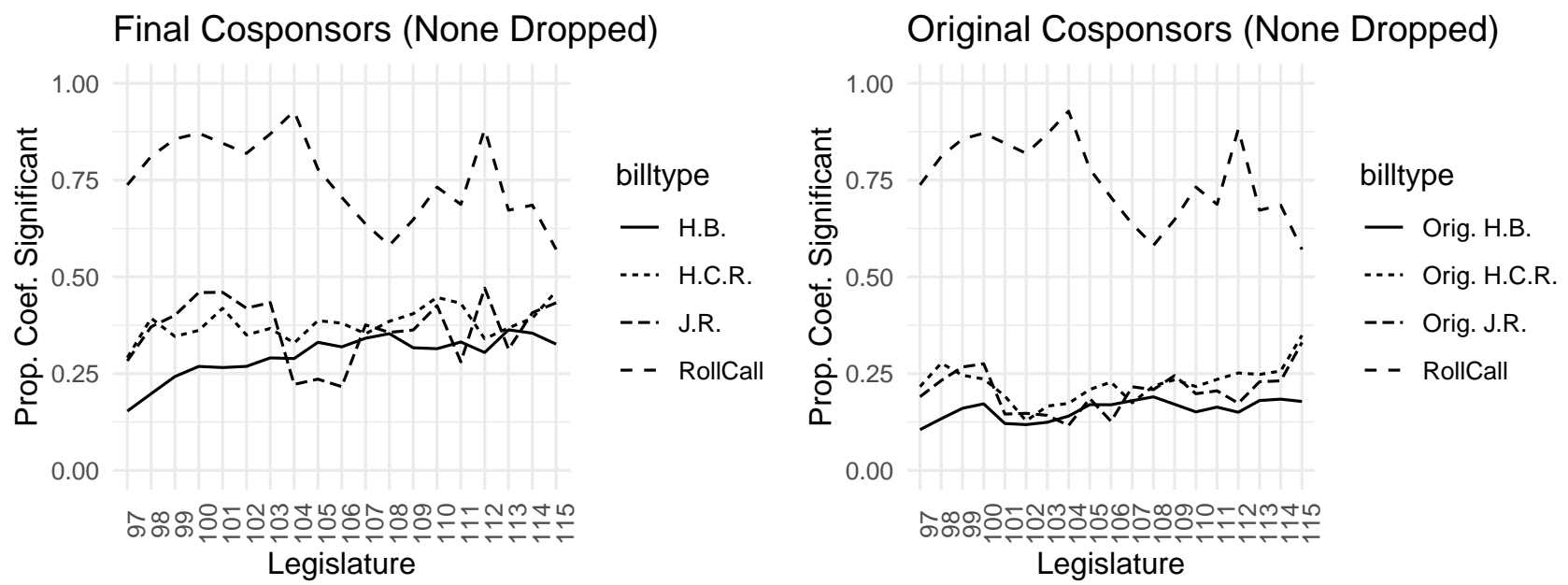

To visualize the extent to which this is a problem for understanding the true dimensionality of cosponsorship behavior, I estimated the dimensionality on all roll-call votes and on all cosponsorship items, whether or not they reached the lopsided threshold. Again, this can be done by using unbiased ideal points - in this case I am using roll-call ideal points - and running one regression probit model per each item of behavior - either roll-call or cosponsorship 
behavior. Then, we look at the proportion of times those regression models have significant coefficients, and that tells us the extent to which the first dimension explains cosponsorship or roll-call behavior.

\section{Figure 5: Assessment of Dimensionality (Eleven Dropped)}

Final Cosponsors (Min: 11 yeas and 11 nays) Original Cosponsors (Min: 11 yeas and 11 ।
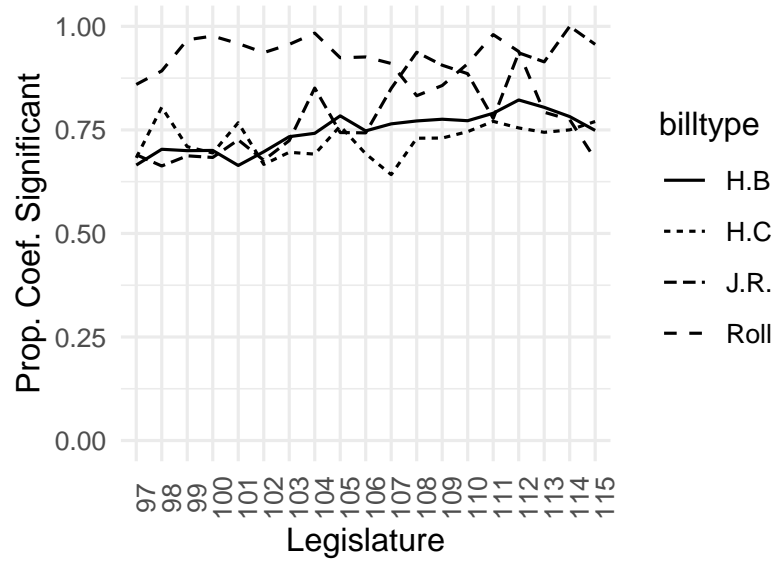

- H.B.

-... H.C.R.

--. J.R.

- - RollCall

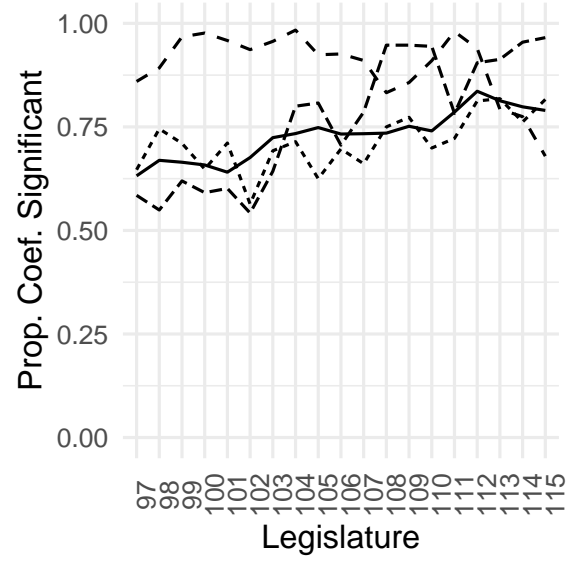

billtype

- Orig. H.B

-... Orig. H.C.R.

-- Orig. J.R.

- - RollCall

Figure 4 shows the proportion of significant coefficients for roll-call and cosponsorship behavior on House Bills, House Concurrent Resolutions and on House Joint Resolutions $4^{4}$ This process was repeated for both final cosponsors and original cosponsors. The figure clearly shows that there is a large portion of cosponsorship behavior that is not explained by the first dimension. The figure also shows that the dimensionality of original cosponsorship behavior is higher than final cosponsorship behavior. Interestingly, when lopsided votes are included, even roll-call behavior seems to be higher-dimensional in certain periods than what would have been expected. In contrast, Figure 5 shows these two plots repeated on the subset of bills where there are at least 11 yeas and 11 nays or 11 signatures and 11 non-signatures. As can be seen, the exclusion of lopsided data, which is very prevalent in cosponsorship data, makes us extremely overestimate the extent to which cosponsorship behavior is predicted by the first dimension.

\footnotetext{
${ }^{4}$ I dropped Amendments because they are usually single-author items, and therefore the amount of Amendment behavior explained by the first-dimensional ideal points is virtually $0 \%$ in all Congresses.
} 


\section{$9 \quad$ Analyzing Single-Author Bills}

The inclusion of lopsided cosponsorship data in the analysis of dimensionality performed in the previous section suggested that a large portion of cosponsorship data cannot be explained by the first dimension. That is to say, it provided evidence that more than one dimension of legislative preferences are relevant to the understanding of legislative politics. This conclusion depends to a large extent, however, on the fact that a large portion of cosponsorship behavior consists of lopsided votes and - as a particular subset of lopsided votes - single-author bills.

That the conclusion of multidimensional preferences depends on a large portion of singleauthor bills may seem like cheating to some readers. For cannot single-author bills be a product of unidimensional preferences? Luckily, if preferences were strictly unidimensional, we can produce quite clear predictions about where single-author bills are likely to occur. Specifically, if true preferences are strictly unidimensional, then single-author bills would be more likely in the ideological extremes than in the center. This is because for a singleauthor bill to occur on a single dimension, there must be a cutpoint that either separates the leftmost legislator from everyone else or the rightmost author from everyone else. Any cutpoint that takes place towards the center of the distribution of legislator ideal points will include more legislators on each side of the cutpoint, leading to more predicted cosponsors to the bill. Therefore, a simple way to observe whether single-author bills conform to these unidimensional expectations would be to create histograms of the number of times legislators sponsored single-author bills. If single-author bills conform to underlying unidimensional preferences, we would expect the frequency of single-author bills to be much higher in the extremes than in the center of the first dimension. However, if preferences are not well explained by a single dimension, then the distribution of single-author bills should be more erratic and unstructured.

Figure 6 shows the histograms of single-author bills according to first-dimensional preferences. These histograms were performed on all final cosponsorship data, but histograms performed on all original cosponsorship data reveal the same trends. In general, these his- 
tograms show that single-author bills are not systematically clustered towards the extremes of first-dimensional preferences. The sole exception may be the 105th Congress where one extreme legislator did have a high number of single-author bills, but in all other legislatures the number of single-author bills seem to be idiosyncratic to specific legislators, and clustered in a seemingly unstructured and random way. Given that these histograms do not conform to what we would expect single-author bills to look like if preferences were truly unidimensional, they also suggest that unrestricted legislative preferences are of a higher dimensionality than the literature has generally suggested. 


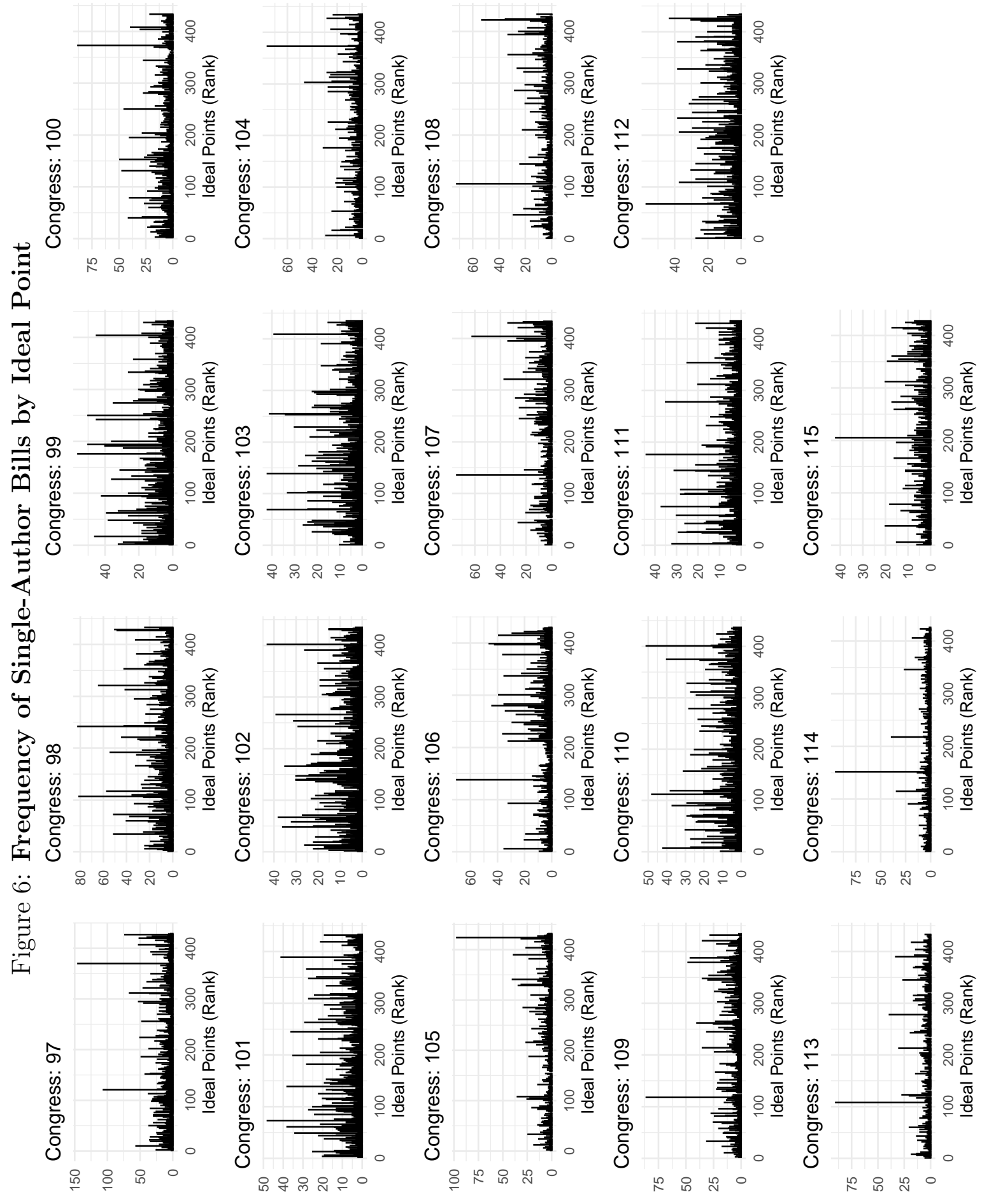




\section{Conclusions}

The first dimension of legislative preferences, which is often considered to be a partisan/ideological dimension, is definitely important to our understanding of legislative behavior. The fact that this dimension can be uncovered, in a mostly unbiased manner, from two different data sets that are produced through different data generating processes, suggest that this one dimension clearly exists and is strongly delimited in the minds of legislators. Therefore, the first finding of this paper is that the first dimension of legislative preferences is important.

However, is the first dimension of legislative preferences the sole motivation behind all legislative behavior - as required by PIE explanations of legislative stability? The empirical analysis of this paper suggest that it is not. I found that $0 \%$ of Amendment behavior and only around 25-30\% of original and final cosponsorship behavior for all other kinds of bills is explained by the first dimension of legislative preferences. Furthermore, bills that are classified as lopsided do not conform to what we would expect from legislators that have unidimensional behavior. If all behavior was unidimensional, most lopsided cosponsorship behavior would be found among peripheral legislators on the first dimension, and not among central legislators on the first dimension. This prediction is not supported by empirical observations of cosponsorship behavior.

The findings of high-dimensional cosponsorship behavior and low-dimensional roll-call behavior suggest that PIEs are not likely, and that SIEs are more likely to explain how legislative stability actually is created. As mentioned in the introduction while both PIEs and SIEs expect that behavior such as roll-call voting, they create different expectations for behavior such as cosponsorship behavior, which is not believed to be strongly constrained by legislative institutions. A PIE would expect both roll-call and cosponsorship behavior to be unidimensional, because they are both merely an expression of the single-dimension of legislative preferences (Krehbiel, 1998). In contrast, a SIE expects roll-call behavior to be unidimensional, but cosponsorship behavior to be multidimensional, as cosponsorship is less constrained by institutions it should reflect individual, multidimensional preferences, before 
institutions constrain legislators into producing unidimensional roll-call behavior (Shepsle and Weingast, 1981). My empirical analysis, which shows multidimensional cosponsorship behavior paired with unidimensional roll-call behavior, supports the SIE argument.

The main implication for these findings is that scholars of legislative studies should no longer be allowed to assume the unidimensionality of legislative preferences without justifying that assumption. There may be some situations where SIEs imply that legislative outcomes will be similar to the preferences of the median legislator on the first dimension (Shepsle and Weingast, 1981), but theories of legislative parties have argued that parties may be able to use legislative institutions to create outcomes that are closer to the party and further from the median legislator than may be otherwise expected (Cox and McCubbins, 1993, 2005). Furthermore, certain theories like conditional party government have even suggested that the way institutions produce stability may depend on the preference composition of political parties Aldrich, 1989, 2011; Aldrich, Berger and Rohde, 2002; Aldrich, Rohde and Tofias, 2007). Therefore, if there is some reason to expect legislative outcomes to be produced near the preferences of the median legislator, then unidimensionality may be used as a simplifying assumption, but if median outcomes (on the first dimension) are not the norm of a given chamber, then the assumption of unidimensionality seems unjustified. Especially because medians usually do not exist in multidimensional settings.

\section{Avenues for Future Research}

A growing number of authors have begun to move in a more multidimensional direction. For example, Aldrich (2011) and Aldrich, Rohde and Tofias (2007) have modified conditional party government theory to function in multiple dimensions. Roberts, Smith and Haptonstahl (2015) have provided evidence to show that roll-call voting in the US House of Representatives is multidimensional when ideal points are estimated over subsets of data rather than on all pooled data. Jochim and Jones (2012) similarly subdivided votes into issue areas and found that voting within these issue areas was more multidimensional than 
voting seemed when all data was pooled together-although increasing polarization leads to more unidimensional voting in a larger portion of issue areas as time goes by. Dougherty, Lynch and Madonna (2014) and Wright and Schaffner (2002) have found that even when roll-call behavior is unidimensional, that does not imply that preferences are unidimensional, as preferences constrained by institutions could present themselves as more unidimensional than unconstrained preferences would have been otherwise. Lee (2009) found that political parties act in very partisan manners even on non-ideological issues because they wish to differentiate themselves from each other and position themselves for political advantageleading legislative behavior to be explained by something "beyond ideology." Noel (2012) argued that ideology - a "coalition of ideas" - and parties - a "coalition of people" - may be collinear now, but in the past they were regarded as two separate forces. In short, in addition to the findings of this paper, a growing number of legislative scholars have been arguing that there may be more to legislative behavior than the single ideological dimension can account for.

In order to refine spatial models to account for this multidimensionality, I propose three research avenues that would be useful to explore going forward. A first avenue for future research is for academics to exert more effort in modeling multidimensionality explicitly, and for academics to create and refine theories of how political parties may function in multidimensional settings. Very interesting work has been carried out in this respect by Bianco, Jelizakov and Sened (2004); Bianco and Sened (2005); Bianco et al. (2006, 2008) and Jeong et al. (2014). All these authors have explicitly modeled legislative preferences in multidimensional preferences, and they derived clear predictions of where we would expect legislative outcomes given these multidimensional preferences. These expectations were derived by using well-known, but under-utilized, concepts like the "Yolk" and "uncovered set" of multidimensional preferences.

However, in this literature the conceptualization of what "party influence" may mean in multidimensional settings is still unclear (Bianco and Sened, 2005). One option would be 
to define a "partisan outcome" as uncovered sets that are closer to one party than another. However, this definition would suffer from the limitation that "partisan outcomes" would be observationally equivalent to the outcome you would expect from non-partisan legislators, allowing for no effect of parties on outcomes independent of preferences (Krehbiel, 1993). Another option would be to define "party influence" as the agenda setting powers used by the party to subset possible outcomes inside the uncovered set so that even within the uncovered set legislative outcomes would be closer to the majority party than expected (Bianco and Sened, 2005). However, this option would also provide counterintuitive expectations. For example, Conditional Party Government expects that while more polarized between parties and more homogeneous within parties, the stronger partisan effects we should expect from a legislature (Aldrich, Berger and Rohde, 2002). However, if we take "party influence" to mean agenda setting within the uncovered set, then ironically the more strongly met "the conditions" the less party effects we should expect. This is because the stronger the conditions, presumably the smaller the uncovered set, and the smaller the uncovered set the less opportunity there is for parties to affect outcomes through agenda-setting - allowing for less room for partisan influence independent of preferences. Finally, a third option for conceptualizing "partisan influence" in multidimensional spaces may be based on the idea that parties have super-majoritarian internal institutions (Aldrich, 2011). If this were the case, an alternative, partisan prediction to the uncovered set for the floor as a whole may be a qualified majority uncovered set for each party. In this way separate predictions for "partisan" and "non-partisan" outcomes can be created given the same multidimensional preferences of legislators. $5^{5}$

In addition to clarifying the expectations of partisan and non-partisan outcomes in multidimensional spaces, a second avenue for research may be to give more importance to how

\footnotetext{
${ }^{5}$ For interactive graphics that show majoritarian uncovered sets for the floor as a whole, and supermajoritarian uncovered sets for each party, see my website: http://shiny.legisdata.org:3838/apps/5_US_house_sen/markdown-eng.rmd Furthermore, an R application for calculating uncovered sets, yolks and median lines for two-dimensional ideal points can be found in my github page: https://github.com/acarrizosa/uset
} 
institutions that are external to the legislature affect the dimensionality of legislative behavior within legislatures. It is well known that the "core" of policies that cannot be beat by any alternative does not exist for majoritarian voting if preferences are multidimensional. However, as the threshold to pass a policy rises from majoritarian to supermajoritarian or even unanimity, then the "core" exists fore more and more dimensions Aldrich, 2011; Tsebelis, 2002). If legislators anticipate supermajoritarian institutions and preemptively behave in a manner that conforms to those supermajoritarian institutions, as many studies on veto dynamics suggest legislators probably do (Cameron and McCarty, 2004; Cameron, 2010), then we might expect legislators that function under systems where more supermajoritarian constraints are placed on them to behave in a more unidimensional manner. In fact some authors have argued that legislators in the U.S. House of Representatives behave in such a partisan manner because they attempt to position themselves in relation to the positions adopted by the president (Lee, 2009). Given that there is a high level of variance in dimensionality measures from one state to another in subnational studies of legislative behavior (Shor, Berry and McCarty, 2010; Shor and McCarty, 2011) a very promising avenue for research would be to test the extent to which supermajoritarian institutions that are external to the legislature affect the dimensionality of roll-call voting through legislators' anticipation of the effects of those institutions.

A final avenue for future research may be to continue with the research agenda proposed by Talbert and Potoski (2002) and Jones, Talbert and Potoski (2003). As my findings have shown above, there did seem to be a reduction of dimensionality of cosponsorship behavior when we moved from original cosponsors to final cosponsors. Furthermore, we saw that dimensionality decreases substantially by the time bills are voted on. Pairing cosponsorship behavior with roll-call behavior could allow us to see which bills get censored before receiving a floor vote, and which bills are able to make it through. By doing this we may be able to find certain legislators that are more likely to sponsor bills that reach the floor than others, and this might serve as an indicator for positive legislative power. 
Paired with multidimensional partisan and non-partisan expectations derived from floor and supermajoritarian, party uncovered sets, using cosponsorship data to more directly observe what agenda setting powers lets through and what it doesn't would certainly be a fruitful way forward.

Overall then, my findings in this paper contributes a further argument for why we should put more effort into modeling legislative behavior in multidimensional settings. Realistically, this expectation seems to conform more closely to the incentives that legislators actually face - as shown by the high-dimensional preferences of cosponsorship behavior presented in this paper. However, we still do not have a strong understanding of what the different ways are through which these multidimensional preferences can be compressed onto unidimensional roll-call behavior - which we also observed in the House of Representatives. Clarifying multidimensional expectations for partisan outcomes in legislatures, exploring the effects of supermajoritarian institutions that are external to the legislature on roll-call behavior, and directly observing which bills agenda setting lets through of all those that were sponsored by legislators are promising ways forward to help deepen our understanding of legislative dynamics under assumptions of multidimensional preferences. 


\section{References}

Aldrich, John. 1989. Power and Order in Congress. In Home Style and Washington Work: Studies of Congressional Politics. University of Michigan Press pp. 219-246.

Aldrich, John. 2011. Why parties?: A Second Look. University of Chicago Press.

Aldrich, John, David W. Rohde and Michael Tofias. 2007. One D is not Enough: Measuring Conditional Party Government , 1887-2002. In Party, Process, and Political Change in Congress Volume 2. pp. 102-112.

Aldrich, John, Mark Berger and David W. Rohde. 2002. The Historical Variability in Conditional Party Government, 1877-1994. In Party, Process, and Political Changes in Congress. Stanford University Press chapter Ch. 2.

Alemán, Eduardo, Ernesto Calvo, Mark P. Jones and Noah Kaplan. 2009. "Comparing cosponsorship and roll-call ideal points." Legislative Studies Quarterly 34(1):87-116.

Arrow, Kenneth. 1951. Social Choice and Individual Values. John Wiley and Sons, Inc.

Bianco, Wiliam and Itai Sened. 2005. "Uncovering Evidence of Conditional Party Government: Reassessing Majority Party Influence in Congress and State Legislatures." American Political Science Review .

Bianco, William, Ivan Jelizakov and Itai Sened. 2004. "The Uncovered Set and the Limits of Legislative Action." Political Analysis .

Bianco, William, Michael Lynch, Gary Miller and Itai Sened. 2006. "A Theory Waiting to Be Discovered and Used: A Reanalysis of Canonical Experiments on Majority-Rule Decision Making." The Journal of Politics .

Bianco, William, Michael Lynch, Gary Miller and Itai Sened. 2008. "The Constrained Instability of Majority Rule: Experiments on the Robustness of the Uncovered Set." Political Analysis .

Black, Duncan. 1948. "On the Rationale of Group Decision-making." Journal of Political Economy (56):23-34.

Cameron, Charles. 2010. "The Presidential Veto." The Oxford Handbook of the American Presidency 9780199238:1-20.

Cameron, Charles and Nolan McCarty. 2004. "Models of Vetoes and Veto Bargaining." Annual Review of Political Science 7(1):409-435.

Clinton, Joshua, Simon D. Jackman and Douglas Rivers. 2004. "The Statistical Analysis of Roll Call Data." American Political Science Review 98(2):355-370.

Converse, Philip. 1964. Ideology and Discontent. chapter The Nature of Belief Systems in Mass Publics. 
Cox, Gary W. and Mathew D. McCubbins. 1993. Legislative Leviathan. University of California Press.

Cox, Gary W. and Mathew D. McCubbins. 2005. Setting the agenda: Responsible party government in the U.S. house of representatives.

Desposato, Scott W., Matthew C. Kearney and Brian F. Crisp. 2011. "Using cosponsorship to estimate ideal points." Legislative Studies Quarterly 36(4):531-565.

Dougherty, Keith L., Michael S. Lynch and Anthony J. Madonna. 2014. "Partisan Agenda Control and the Dimensionality of Congress." American Politics Research 42(4):600-627.

Fowler, James. 2006. "Connecting the Congress: A Study of Cosponsorship Networks." Political Analysis.

Hug, Simon. 2010. "Selection effects in Roll Call Votes." British Journal of Political Science

Jackman, Simon. 2001. "Society for Political Methodology Multidimensional Analysis of Roll Call Data via Bayesian Simulation : Identification, Estimation, Inference , and Model Checking." Political Analysis 9(3):227-241.

Jeong, Gyung-Ho, William Lowry, Gary Miller and Itai Sened. 2014. "How Preferences Change Institutions: The 1978 Energy Act." The Journal of Politics .

Jochim, Ashley and Bryan Jones. 2012. "Issue Politics in a Polarized Congress." Political Research Quarterly .

Jones, Bryan, Jefrey Talbert and Matthew Potoski. 2003. Uncertainty in American Politics. Cambridge University Press chapter Uncertainty and Political Debate: How the Dimensionality of Political Issues Gets Reduced in the Legislative Process, pp. 118-136.

Kessler, Daniel and Keith Krehbiel. 1996. "Dynamics of Cosponsorship." American Political Science Review 90(3):555-566.

Krehbiel, Keith. 1993. "Where's the Party?" British Journal of Political Science.

Krehbiel, Keith. 1998. Pivotal Politics: A Theory of U.S Lawmaking. University of Chicago Press.

Lee, Frances. 2016. Insecure Majorities: Congress and the Perpetual Campaign. University of Chicago Press.

Lee, Frances E. 2009. Beyond Ideology: Politics, Principles, and Partisanship in the U.S. Senate. University of Chicago Press.

Lewis, Jeffrey, Keith Poole, Howard Rosenthal, Adam Boche, Aaron Boche, Aaron Rudkin and Luke Sonnet. 2020. Voteview: Congressional Roll-Call Votes Database. .

URL: https://voteview.com/ 
Mayhew, David. 1974. Congress: The Electoral Connection. Yale University Press.

McCarty, Nolan. 2016. "In Defense of DW-NOMINATE." Studies in American Political Development .

Noel, Hans. 2012. Political ideologies and political parties in America.

Poole, Keith. 2005. Spatial Models of Parliamentary Voting. Cambridge University Press.

Poole, Keith T. and Howard Rosenthal. 1997. "Congress: A Political-Economic History of Roll Call Voting." Congress \& the Presidency .

Ramey, Adam. 2015. "Weighing the Alternatives: Preferences, Parties, and Constituency in Roll-Call Voting." The Journal of Politics .

Roberts, Jason, Steven Smith and Stephen Haptonstahl. 2015. "The Dimensionality of Congressional Voting Reconsidered." American Politics Research .

Shepsle, Kenneth and Barry Weingast. 1981. "Structure-Induced Equilibrium and Legislative Choice." Public Choice 37(3):503-519.

Shor, Boris, Christopher Berry and Nolan McCarty. 2010. "A Bridge to Somewhere: Mapping State and Congressional Ideology on a Cross-Institutional Common Space." Legislative Studies Quarterly.

Shor, Boris and Nolan McCarty. 2011. "The Ideological Mapping of American Legislatures." American Political Science Review .

Smith, Steven S. 2007. Party influence in congress.

Talbert, Jeffrey and Matthew Potoski. 2002. "Setting the Legislative Agenda: The Dimensional Structure of Bill Cosponsoring and Floor Voting." The Journal of Politics .

Tsebelis, George. 2002. Veto Players: How Political Institutions Work. Princeton University Press.

Tullock, Gordon and Geoffrey Brennan. 1981. "Why so Much Stability." Public Choice .

Wright, Gerald C and Brian F Schaffner. 2002. "The Influence of Party: Evidence from the State Legislatures." 96(2):367-379. 